\title{
Influence of Coke and Graphite on the Decomposition and Melting Behavior of a Mold Flux
}

\author{
Edgardo Benavidez, Leandro Santini, Alejandro Martín and Elena Brandaleze \\ Facultad Regional San Nicolás, Universidad Tecnológica Nacional, San Nicolás 2900, Argentina
}

\begin{abstract}
The melting kinetics of mold fluxes used in steel continuous casting represents a fundamental factor to be considered in order to obtain a quality product without superficial defects and also to avoid production problems. This melting stage is controlled mainly by the type and amount of carbonaceous material added to the powder. In this work, structure, particle size and morphology of two carbonaceous materials: petroleum coke and synthetic graphite were analyzed. Both carbonaceous materials were separately added to a decarburized commercial mold flux. The melting behavior was monitored by HSM (hot stage microscopy) and a melting interval was identified using critical temperatures. A higher fusion rate, as inverse of melting interval, was observed in powder with coke addition. This fact was associated to a lower crystalline degree and a finer PSD (particle size distribution) presented by petroleum coke. Different values of the activation energy of decomposition were related to fusion rate of both mold fluxes. Higher rate of changes in activation energy during the progress of the reaction was observed in the sample with coke. This fact is associated to a faster change in the surface area of coke particles.
\end{abstract}

Key words: Carbonaceous materials, mold fluxes, steel casting, melting behavior.

\section{Introduction}

Mold fluxes or casting powders are manufactured from several minerals such as wollastonite, feldspars, carbonates, quartz, and fluorite. They also contain free carbon in their compositions which is incorporated through different carbonaceous materials such as graphite, coke or carbon black [1,2]. During the steel continuous casting process, these powders are added to the liquid steel surface forming three different layers: powdered, sintered, and molten. In this stage, carbonaceous material decomposes and forms $\mathrm{CO}_{\mathrm{x}}$ (gas) which protects the steel surface from oxidation. The molten layer forms a "liquid slag pool"; this molten slag penetrates in the gap between the copper mould wall and the solidified steel shell [3]. Percentage, size, morphology and type of carbonaceous material added $[4,5]$ are associated to melting behavior of mold fluxes.

Melting rate is one of the main properties because it

Corresponding author: Edgardo Benavidez, Ph.D., professor, research fields: slags, refractories materials. controls the depth of the liquid pool which is necessary to ensure proper lubrication and uniform heat transfer during steel solidification [6]. A minimum depth of the liquid pool must be guaranteed to pour the melt into the gap between the mold plate and the solidified steel shell during down stroke [7]. On the other hand, an excess of pool thickness forms an excessive slag rim that can prevent the slag supply into the gap [7].

Melting behavior of mold fluxes depends on the reactivity of the added carbonaceous material; i.e., on the activation energy of the materials to be decomposed. The combustion reactivity of different carbonaceous materials: synthetic graphite, vein graphite, expandable graphite, amorphous graphite, petroleum coke and metallurgical coke, was studied by Singh et al. [8]. They associated this reactivity with structural parameters (relative amounts of amorphous and crystalline phases) of carbonaceous materials. The melting behavior of mold fluxes elaborated with different percentages of these carbonaceous materials was studied. 
In Ref. [9] the decomposition kinetics of two casting powder samples was studied: one with petroleum coke and the other with synthetic graphite, TG (thermogravimetric) data, obtained at different heating rates $\left(\beta=5,7,10,14^{\circ} \mathrm{C} / \mathrm{min}\right)$ in air, were analyzed by non-isothermal kinetic methods to estimate the activation energy of decomposition (free carbon reaction with the atmosphere). Besides, a first order of the reaction was estimated for both powders. From these activation energy values an MDC (master decomposition curve) was constructed in Ref. [10]. From the MDC, the time needed to produce a specific degree of decomposition at certain temperature was calculated. The results predicted by this curve were experimentally verified. The MDC of both casting powders permitted to estimate the degree of decomposition (or carbon removal) under different thermal conditions.

The present work compares the melting behavior of two mold fluxes using a commercial mold flux as a base powder, one with addition of petroleum coke and the other with synthetic graphite, both similar to those studied by the authors in Refs. [9, 10]. The analysis of the behavior in the melting stage was carried out through a hot microscopy study by which the critical temperatures of the powders were determined. This melting behavior was related to structure (crystalline/amorphous), morphology and PSD (particle size distribution) of coke and graphite.

\section{Materials and Methods}

The chemical composition of the commercial casting powder (base) is presented in Table 1. The basicity (ratio $\mathrm{Ca} / \mathrm{SiO}_{2}$ ) of this powder is 0.87 .

The base casting powder was heated at $800{ }^{\circ} \mathrm{C}$ during 6 hours in air to eliminate free carbon (decarburization process). Then, $15 \mathrm{wt} \%$ of petroleum coke (sample C) or synthetic graphite (sample G) was added to decarburized base powder.

The morphology of both carbonaceous materials was observed by SEM (scanning electron microscopy) with a Philips 515 microscope.

PSD of coke and graphite was determined by dry sieving. For this, $100 \mathrm{~g}$ of carbonaceous powders were sieved under mechanical vibration during 5 minutes. The meshes used, according to ASTM (American Standards for Testing and Materials) sieve designation, were: 50, 60, 100, 170, and 200 .

Carbonaceous materials structures were studied by XRD (X-ray diffraction) with a Philips 1390 diffractometer, using $\mathrm{Cu} \mathrm{K} \alpha$ radiation. The step size was $2 \theta=0.025^{\circ}$ and spectra of samples were obtained in the $2 \theta=5^{\circ}-80^{\circ}$ diffraction region.

The melting behavior was characterized by HSM (hot stage microscopy). Mold powders $(\approx 155 \mathrm{mg}$ ) were uniaxially pressed $(100 \mathrm{MPa})$ to obtain cylindrical samples: $5 \mathrm{~mm}$ in diameter and $\approx 5 \mathrm{~mm}$ in height. The samples were placed on an alumina support. The temperature was registered by a thermocouple located under the alumina support. The measurements were conducted at air from room temperature (initial temperature $T_{\mathrm{I}}=20{ }^{\circ} \mathrm{C}$ ) at a heating rate of $5^{\circ} \mathrm{C} / \mathrm{min}$. The change of shape was registered by a camera and the characteristic points, indicated as critical temperatures, were:

(1) deformation temperature $\left(T_{\mathrm{D}}\right)$ : the sample height is $75 \%$ of its initial height,

(2) hemispherical temperature $\left(T_{\mathrm{H}}\right)$ : the sample height is $50 \%$ of its initial height, and

Table 1 Chemical composition of the base mold flux.

\begin{tabular}{ll}
\hline Compound & wt \% \\
\hline $\mathrm{SiO}_{2}$ & 31.0 \\
$\mathrm{CaO}$ & 27.0 \\
$\mathrm{Na}_{2} \mathrm{O}$ & 11.0 \\
$\mathrm{Al}_{2} \mathrm{O}_{3}$ & 4.4 \\
$\mathrm{MgO}$ & 1.8 \\
$\mathrm{MnO}$ & 0.06 \\
$\mathrm{TiO}_{2}$ & 0.20 \\
$\mathrm{Fe}_{2} \mathrm{O}_{3}$ & 1.4 \\
$\mathrm{~K}_{2} \mathrm{O}$ & 0.62 \\
$\mathrm{P}_{2} \mathrm{O}_{5}$ & 0.1 \\
$\mathrm{~F}$ & 9.05 \\
$\mathrm{C}$ (free) & 4.0 \\
\hline
\end{tabular}


(3) fluidity temperature $\left(T_{\mathrm{F}}\right)$ : the sample height is $25 \%$ of its initial height.

\section{Results and Discussion}

\subsection{Characteristics of Carbonaceous Materials}

Fig. 1 shows XRD spectra of graphite and coke. XRD diffraction pattern of the coke showed only one broad peak, between $2 \theta=20^{\circ}-30^{\circ}$, corresponding to a type of fully amorphous carbon. For synthetic graphite, the peaks corresponding to only one crystalline phase, namely graphite (main peak in $2 \theta=26.6^{\circ}$ ) were found Thus, synthetic graphite exhibits a greater order of crystallinity than petroleum coke. Therefore, because the reactivity of carbonaceous materials depends on the graphitization degree of carbon crystals, the XRD suggests that petroleum coke should be more reactive than synthetic graphite.

From the sieving test, the retained mass in each mesh (in wt\%) is presented in Table 2.

The CPFT (cumulative percent finer than) distribution, corresponding to graphite and coke, is showed in Fig. 2.

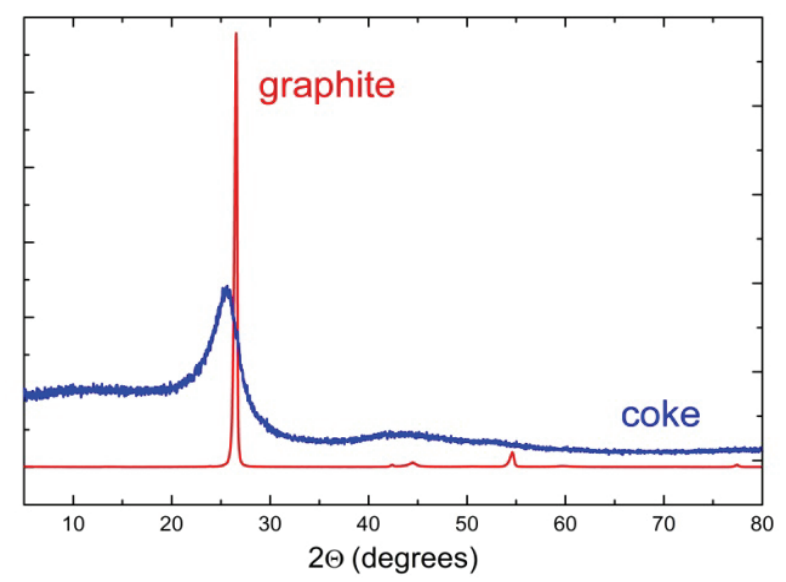

Fig. 1 XRD pattern of coke and graphite.

Table 2 Retained mass (wt \%) in each mesh.

\begin{tabular}{llll}
\hline $\begin{array}{l}\text { Mesh } \\
\text { ASTM }\end{array}$ & $\begin{array}{l}\text { Sieve opening } \\
(\mu \mathrm{m})\end{array}$ & $\begin{array}{l}\text { Coke } \\
(\mathrm{wt} \%)\end{array}$ & $\begin{array}{l}\text { Graphite } \\
(\mathrm{wt} \%)\end{array}$ \\
\hline 50 & 300 & 5.6 & 24.2 \\
60 & 250 & 6.4 & 8.2 \\
100 & 150 & 24.8 & 20.9 \\
170 & 90 & 20.1 & 19.2 \\
200 & 75 & 29.7 & 12.9 \\
$>200$ & $<75$ & 12.5 & 14.1 \\
\hline
\end{tabular}

From these curves the mean particle size $\left(\mathrm{DP}_{50}\right)$ was obtained. Parameter $\mathrm{DP}_{50}$ indicates the particle size at $50 \%$ on the cumulative distribution. The values of $\mathrm{DP}_{50}$ were $112 \mu \mathrm{m}$ for coke and $170 \mu \mathrm{m}$ for graphite. Thus, from these values it is observed that coke has a PSD finer than graphite.

Morphology of coke particles is spherical/round in shape (Fig. 3). Coke particles are around $10 \mu \mathrm{m}$ in size but they form agglomerates. In Fig. 3 it is observed agglomerates higher than $100 \mu \mathrm{m}$.

Fig. 4 shows typical graphite particles morphology consists of elongated grains (like flakes).

Summarizing, synthetic graphite presents a higher deviation from the spherical shape, a larger average particle size, and a greater degree of crystallization than petroleum coke.

\subsection{Melting Behavior of Mold Fluxes}

The images corresponding to the determination of
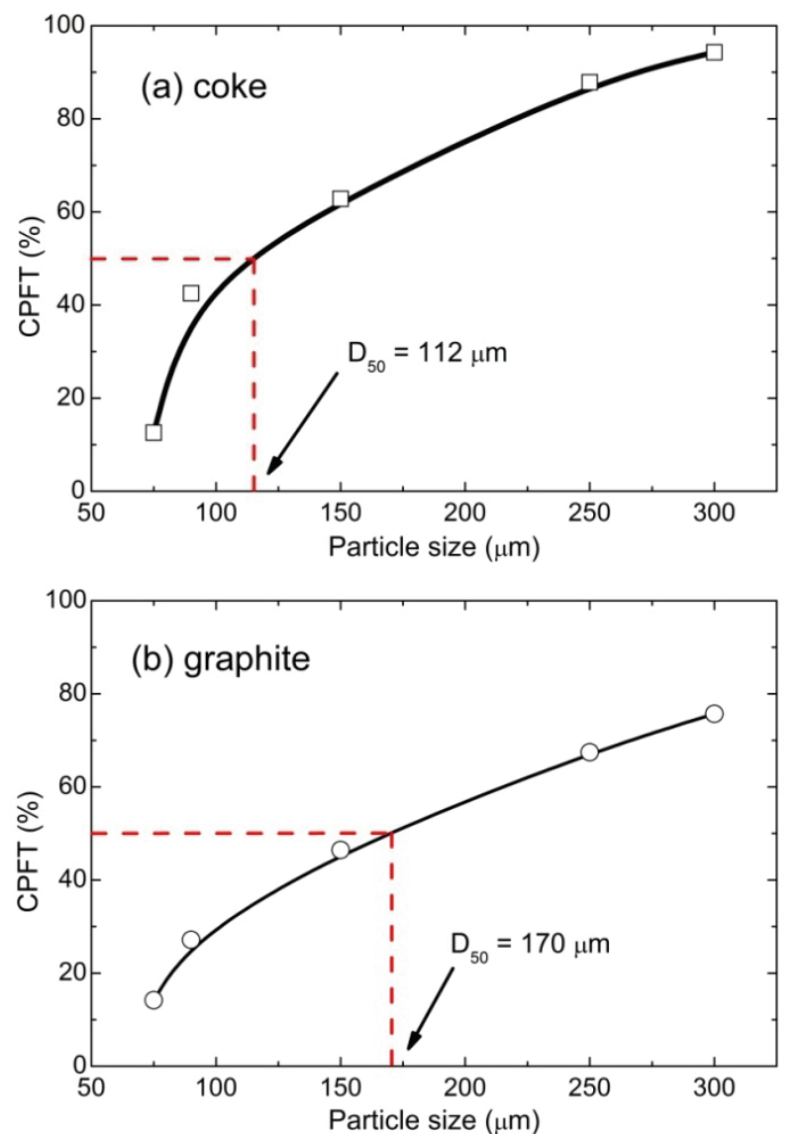

Fig. 2 PSD of (a) petroleum coke and (b) synthetic graphite. 


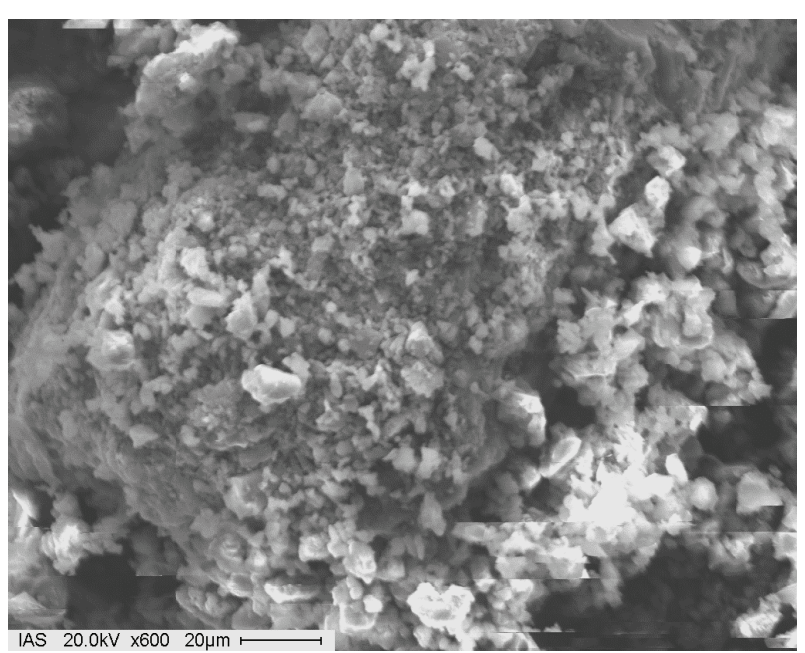

Fig. 3 SEM micrograph showing the morphology of coke particles $(\times 600)$.

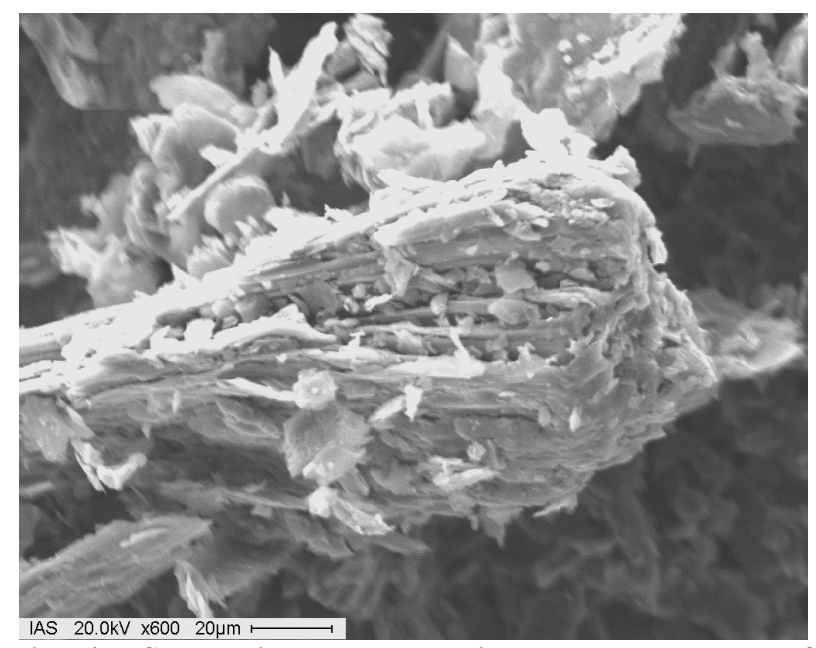

Fig. 4 SEM micrograph showing the morphology of graphite particles $(\times 600)$.

the critical temperatures of both samples (C and $\mathrm{G})$ are presented in Fig. 5.

The values of $T_{\mathrm{D}}$ (deformation), $T_{\mathrm{H}}$ (hemisphere) and $T_{\mathrm{F}}$ (fluidity) are listed in Table 3.

The temperature of deformation is associated to the beginning of the fusion, while the temperature of fluidity is linked to the end of the fusion. Thus, the difference between the fluidity temperature and the deformation temperature $\left(T_{\mathrm{F}}-T_{\mathrm{D}}\right)$ can be defined as the "melting interval": $\Delta T_{\mathrm{M}}$. Because HSM tests are performed at constant heating rate, then $\Delta T_{\mathrm{M}}=T_{\mathrm{F}}-$ $T_{\mathrm{D}}$, is inversely proportional to the "fusion rate". In this way, $\Delta T_{\mathrm{M}}$ (sample $\mathrm{C}$ ) $=28{ }^{\circ} \mathrm{C}$ and $\Delta T_{\mathrm{M}}$ (sample $\mathrm{G})=53{ }^{\circ} \mathrm{C}$. According to the values of the melting interval, sample C (with coke) exhibits a higher fusion rate than sample $\mathrm{G}$ (with graphite).

In Ref. [9] the activation energy (E) associated to decomposition of samples $\mathrm{C}$ and $\mathrm{G}$ was obtained by four non-isothermal methods: OFW (Ozawa-Flynn-Wall), KAS (Kissinger-Akahira-Sunose), $\mathrm{K}$ (Kissinger), and $\mathrm{AB}$ (Augis-Bennet). Table 4 summarizes the values of the activation energy obtained by each method.

All these techniques presented lower values of $E$ in sample $\mathrm{C}$. From these data, mean values of activation energy $E \approx 48 \mathrm{~kJ} / \mathrm{mol}$ and $E \approx 67 \mathrm{~kJ} / \mathrm{mol}$ were assigned to samples $\mathrm{C}$ and $\mathrm{G}$, respectively [9]. This fact was associated to a higher reactivity of the mold flux with $15 \mathrm{wt} \%$ coke. To construct the MDC, the following values of the activation energy were used: $46 \pm 3 \mathrm{~kJ} / \mathrm{mol}$ for sample $\mathrm{C}$ and $63 \pm 3 \mathrm{~kJ} / \mathrm{mol}$ for sample G [10].

Activation energy values of several carbonaceous materials during combustion were obtained by Shing et al. [8]. For example, activation energies to synthetic graphite $E=73 \mathrm{~kJ} / \mathrm{mol}$ and petroleum coke $E=55$ $\mathrm{kJ} / \mathrm{mol}$ were informed. These values correspond to the
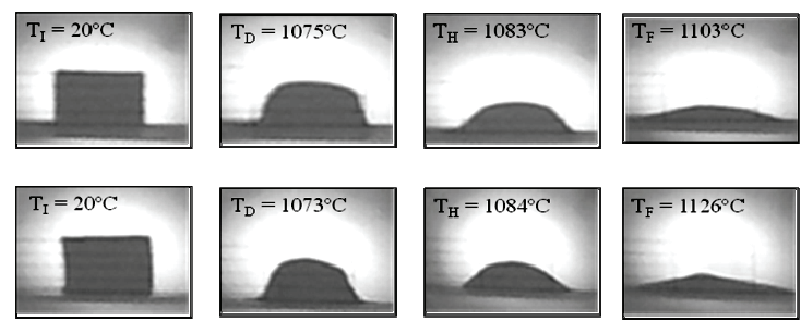

Fig. 5 HSM of sample C (up) and sample G (down).

Table 3 Critical temperatures obtained by HSM.

\begin{tabular}{llll}
\hline Sample & $T_{\mathrm{D}}\left({ }^{\circ} \mathrm{C}\right)$ & $T_{\mathrm{H}}\left({ }^{\circ} \mathrm{C}\right)$ & $T_{\mathrm{F}}\left({ }^{\circ} \mathrm{C}\right)$ \\
\hline $\mathrm{C}$ & 1,075 & 1,083 & 1,103 \\
$\mathrm{G}$ & 1,073 & 1,084 & 1,126 \\
\hline
\end{tabular}

Table 4 Activation energy of the carbonaceous material decomposition [9].

\begin{tabular}{lll}
\hline Method & $\begin{array}{l}\text { Sample C } \\
(\mathrm{kJ} / \mathrm{mol})\end{array}$ & $\begin{array}{l}\text { Sample G } \\
(\mathrm{kJ} / \mathrm{mol})\end{array}$ \\
\hline OFW & 54.0 & 77.2 \\
KAS & 43.1 & 63.2 \\
K & 46.7 & 61.5 \\
AB & 49.2 & 65.8 \\
\hline
\end{tabular}


"composite activation energy" that takes into account both the amorphous part, with lower values of activation energy, and the crystalline part of the carbonaceous materials.

In the present work it is observed that the powder with coke has a higher "fusion rate" (lower melting interval) associated with a lower activation energy of decomposition (greater reactivity). This is due, mainly, to the higher percentage of amorphous structure present in the petroleum coke particles, which causes a faster consumption of the carbonaceous material leaving the mold powder particles unprotected and thus accelerating the fusion process. Moreover, coke's finer PSD contributes to obtaining lower activation energy associated with carbon elimination in sample C.

Although the influence of the percentage of carbonaceous material added has not been analyzed in the present work, an increase in free carbon content increases the fusion rate [6]. However, in Ref. [8] it is emphasized that for contents of carbonaceous material higher than $3.5 \mathrm{wt} \%$ the percentage of free $\mathrm{C}$ added is no longer so influential on the melting rate. In Ref. [7] the dependence of melting rate on free carbon was studied and separate correlations for carbon range between 1.0-4.0 wt $\%$ and between 4.0-7.0 wt $\%$ were obtained. Thus, at very high carbon content, the effect of free-C percentage on the melting rate was observed to have a marginal effect. Owing to the high percentage of free $\mathrm{C}(15 \mathrm{wt} \%)$ added to commercial mold flux in the present work, it is estimated that it is sufficient to completely cover the particles of the decarburized powder.

Table 5 shows the evolution of the activation energies of both powders ( $\mathrm{C}$ and $\mathrm{G}$ ), determined by the OFW and KAS, when the reaction proceeds from $\alpha=0.1$ to 0.9 [9].

It is observed that, in all cases, the value of $E$ decreases as the degree of reaction $(\alpha)$ progresses.

The change of the activation energy $(\Delta E)$, when the decomposition progresses from $10 \%$ to $90 \%$ of the reaction, is calculated following the expression: $\Delta E$ $(\%)=100 \times\left(E_{\alpha=0.9}-E_{\alpha=0.1}\right) / E_{\alpha=0.9}$. According to this expression, the largest decreases in the activation energy, obtained by both methods: OFW and KAS, are presented in the powder with the addition of coke (sample C). This can be associated to the fact that the reaction of the smallest carbonaceous particles with air (oxidation), occurs at lower temperatures and with a lower activation energy than the largest particles.

Zamalloa et al. [11] compared petroleum coke, breeze coke and graphite powders in oxidation experiments under air and $\mathrm{CO}_{2}$. They showed that coke particles display highest oxidation rates and the rates increased with decreased particle size. On the other hand, different specific surface areas are developed in coke particles when combustion reaction progresses [12]. In this way, the oxidation of coke particles modifies their morphology; thus, as claimed by the authors, the BET surface area had a strong influence on the oxidation rate in air [12].

Maximum rates of mass loss $(\mathrm{d} \alpha / \mathrm{d} T)_{\max }$ from samples $\mathrm{C}$ and $\mathrm{G}$ obtained at different heating rates by Benavidez et al. (see Table 2 in Ref. [9]) are listed in Table 6 (in $10^{3} / \mathrm{min}$ ).

From these values it is noted that, for similar heating rates, the highest values of reaction rates $(\mathrm{d} \alpha / \mathrm{d} T)_{\max }$ occur in powder C (15 wt \% coke). For all the heating rates, the maximum of the reaction rate

Table 5 Evolution of the activation energy in samples $\mathbf{C}$ and $G$ according to OFW and KAS methods [9].

\begin{tabular}{llll}
\hline $\begin{array}{l}\text { Sample } \\
\text { (method) }\end{array}$ & $\begin{array}{l}E(\alpha=0.1) \\
(\mathrm{kJ} / \mathrm{mol})\end{array}$ & $\begin{array}{l}E(\alpha=0.9) \\
(\mathrm{kJ} / \mathrm{mol})\end{array}$ & $\begin{array}{l}\Delta E \\
(\%)\end{array}$ \\
\hline $\mathrm{C}(\mathrm{OFW})$ & 76.0 & 33.9 & -55.4 \\
$\mathrm{G}(\mathrm{OFW})$ & 108.8 & 63.2 & -41.9 \\
$\mathrm{C}(\mathrm{KAS})$ & 67.7 & 20.2 & -70.2 \\
$\mathrm{G}(\mathrm{KAS})$ & 100.3 & 48.4 & -51.7 \\
\hline
\end{tabular}

Table 6 Maxima reaction rates [9].

\begin{tabular}{lll}
\hline $\begin{array}{l}\text { Heating rates } \\
\left({ }^{\circ} \mathrm{C} / \mathrm{min}\right)\end{array}$ & $\begin{array}{l}(\mathrm{d} \alpha / \mathrm{d} T)_{\max } \\
\text { sample C }\end{array}$ & $\begin{array}{l}(\mathrm{d} \alpha / \mathrm{d} T)_{\max } \\
\text { sample G }\end{array}$ \\
\hline 5 & 36.6 & 26.6 \\
7 & 46.9 & 33.9 \\
10 & 48.0 & 41.4 \\
14 & 50.4 & 47.6 \\
\hline
\end{tabular}


occurs, in both powders, at about half the degree of decomposition ( $\alpha \approx 48-50 \%$ ).

In this sense, changes in the activation energy with the degree of reaction (oxidation) of graphite must also be taken into account. The catalytic surface roughening as a result of the presence of trace metallic impurities was taken into account during the oxidation kinetics of a natural graphite analysis [13]. Changes in the morphologies of the graphite flakes, due to the oxidation reaction, were studied by Badenhorst and Focke [14]. They observed that the presence of catalytic impurities in two highly crystalline graphites developed macroscopic surface roughness during the initial stage of oxidation. Simulations based on geometric models supported the hypothesis that the conversion function $(\alpha)$ is controlled by the development of complex active surface area geometries.

Summarizing, the mostly amorphous structure and the smaller average particle size of the petroleum coke determine lower activation energy of the decomposition reaction and a higher fusion rate. On the other hand, the greater rate of the degree of reaction $(\mathrm{d} \alpha / \mathrm{dt})$ and the greater variation in the energies of activation $(\Delta E)$ present in sample $C$ are associated with a faster change in the surface area of coke particles as the reaction progresses from $\alpha=0.1$ to 0.9 .

\section{Conclusions}

Petroleum coke and synthetic graphite were added to a commercial mold flux, which was previously decarburized. Based on the temperature of hemisphere and fluidity, determined by HSM, a fusion rate of these casting powders was defined. The analysis of the crystalline structure, the morphology of the particles and the PSD was extremely important to understand the fusion rates and the activation energies of decomposition of these mold fluxes. These characterizations should be taken into account when designing mold powders due to their influence on the control of the thickness of the liquid pool on the upper part of the continuous casting mold.

\section{Acknowledgments}

The authors wish to thank Universidad Tecnológica Nacional (Argentina) for the financial support.

\section{References}

[1] Mills, K. C., Fox, A. B., Li, Z., and Thackray, R. P. 2005. "Performance and Properties of Mould Fluxes." Ironmaking \& Steelmaking 32: 26-34.

[2] Branion, R. V. 1986. "Mold Fluxes for Continuous Casting." Ironmaking \& Steelmaking 13: 41-50.

[3] Brandaleze, E., Di Gresia, G., Santini, L., Martín, A., and Benavidez, E. 2012. "Chapter 7: Mould Fluxes in the Steel Continuous Casting Process." In Science and Technology of Casting Processes, edited by Srinivasan, M. Rijeka: InTech.

[4] Brandaleze, E., Santini, L., Gorosurreta, C., Benavidez, E., and Martin, A. 2007. "Influence of Carbonaceous Particles on the Melting Behaviour of Mold Fluxes at High Temperature." In Proceedings 16th Steelmaking Conference IAS, 363-71.

[5] Wei, E., Yang, Y., Feng, C., Sommerville, I. D., and McLean, A. 2006. "Effect of Carbon Properties on Melting Behavior of Mold Fluxes for Continuous Casting of Steels." Journal of Iron and Steel Research International 13 (May): 22-6.

[6] Kawamoto, M., Nakajima, K., Kanazawa, T., and Nakai, K. 1994. "Design Principles of Mold Powder for High Speed Continuous Casting." ISIJ International 34: 593-8.

[7] Pradhan, N., Ghosh, M., Basu, D. S., and Mazumdar, S. 1999. "Prediction of Slag Pool Thickness in Continuous Casting Mould." ISIJ International 39: 804-8.

[8] Shing, D., Bhhardwaj, P., Yang, Y. D., McLean, A., Hasegawa, M., and Iwase, M. 2010. "The Influence of Carbonaceous Material on the Melting Behaviour of Mould Powder." Steel Research International 81: 1-6.

[9] Benavidez, E., Santini, L., and Brandaleze, E. 2011. "Decomposition Kinetic of Carbonaceous Materials Used in a Mold Flux Design." Journal of Thermal Analysis and Calorimetry 103 (2): 485-93.

[10] Benavidez, E., Santini, L., Martín, A., and Brandaleze, E. 2017. "Master Decomposition Curve of Carbonaceous Materials Used in Casting Powders." Journal of Thermal Analysis and Calorimetry. https://doi.org/10.1007/s10973-017-6892-1.

[11] Zamalloa, M., Ma, D., and Utigard, T. A. 1995. "Oxidation Rates of Industrial Cokes with $\mathrm{CO}_{2}$ and Air." 
ISIJ International 35: 458-63.

[12] Zamalloa, M., and Utigard, T. A. 1995. "Characterization of Industrial Coke Structures." ISIJ International 35: 449-57.

[13] Badenhorst, H., Rand, B., and Focke, W. W. 2010. "Modelling of Natural Graphite Oxidation Using Thermal
Analysis Techniques." Journal of Thermal Analysis and Calorimetry 99: 211-28.

[14] Badenhorst, H., and Focke, W. W. 2012. "Geometric Effects Control Isothermal Oxidation of Graphite Flakes." Journal of Thermal Analysis and Calorimetry 108: 1141-50. 